\title{
The Liverpool urban obstetric flying squad: changing patterns of practice 1965-84
}

\author{
T D R RYAN, G M KIDD
}

\begin{abstract}
Obstetric flying squads operate from most maternity units in the United Kingdom. The 20 years from 1965 to 1984 saw 860 calls being made to the obstetric flying squad in the Liverpool urban area, with striking changes occurring in both the number of calls made and the reasons for making the calls.

Management of the problems encountered has now become almost exclusively conservative, with such procedures as blood transfusion and general anaesthesia being virtually eliminated from practice.
\end{abstract}

\section{Introduction}

The first operational obstetric flying squad was formed in Bellshill in Lanarkshire in 1933 to deal with "the home management of haemorrhage, shock and eclampsia" after Professor E Farquhar Murray originally suggested the idea in $1929 .{ }^{2}$ Since then several reviews have been published, notably by Stabler, ${ }^{34}$ Dewhurst, ${ }^{5}$ Lloyd, ${ }^{6}$ Adamson et al, ${ }^{7}$ Frazer and Tatford, ${ }^{8}$ and Liang, ${ }^{9}$ covering the obstetric flying squads in Newcastle upon Tyne, Manchester, Birmingham, Edinburgh, London, and Bellshill, respectively.

The largest of these studies in terms of the number of calls was that by Liang, who in 1963 presented a review of 1957 calls made to the Bellshill squad from 1933 to 1961 with a more detailed summary of 1499 calls made over the 22 years from 1940 to $1961 .^{9}$ His findings were in broad agreement with all the other main reviews published

Mill Road Hospital, Liverpool

T D R RYAN, MB, FFARCs, consultant anaesthetist

Department of Obstetrics and Gynaecology, Liverpool Maternity Hospital and Mill Road Hospital, Liverpool

G M KIDD, MB, MRCOG, senior registrar up to that time in terms of the apparent need for such a service in both urban and rural communities and in the diseases found and the treatments used.

The findings of a review of 220 patients attended in an exclusively urban environment, published in 1961 by Frazer and Tatford, were similar to Liang's with regard to reasons for calls, treatments given, and requirements for resuscitation. ${ }^{7}$ The only significant difference between the two groups was the complete absence of the practice of giving general anaesthesia at home among Frazer and Tatford's patients, but both papers, and indeed every other both before and after, have emphasised the extremely difficult and hazardous nature of giving anaesthesia during home deliveries, and the writers expressed the opinion that only senior staff should, whenever possible, give the anaesthetic.

A small review of 25 patients in a London urban area by Ferguson and Watson in 1975 suggested that the obstetric flying squad might be unnecessary in modern practice, ${ }^{10}$ though James in 1977 put forward a strong defence of the service in mixed urban and rural areas. ${ }^{11}$ In the same year Zorab and Baskett suggested that mobile resuscitation units might be more beneficial to these patients than specialist obstetric flying squads, ${ }^{12}$ but most of the obstetric units providing the service have ignored this possibility.

In 1980 the Royal College of Obstetricians and Gynaecologists undertook a survey of obstetric flying squad services in the United Kingdom. ${ }^{13}$ It found that, though a great willingness to provide such services still existed, the number of calls had fallen so greatly throughout the country that of 160 units still offering the service (out of 180 returning information), 120 units answered 10 calls or fewer a year. In addition, most staff in the units had noticed quite striking changes in the reasons for calls being made from those described in the large reviews of the 1940s and 1950s and had also at times found difficulty in providing adequately trained team members such as anaesthetists. Many staff expressed reservations about the logistics of continuing the service if home confinements were to increase sharply.

In this paper we set out the findings of our review of 860 calls to 
the Liverpool urban obstetric flying squad during the years 1965-84 to show the changes that have taken place since the last main reviews in the early $1960 \mathrm{~s}$. We have taken Liang's large review as a historical comparison for our findings and hope that our results will provide guidelines for other units in managing their own obstetric flying squad services in the future.

\section{Methods}

The Liverpool obstetric flying squad covers the maternity services of three health districts in the Metropolitan County of Merseyside and is operated on alternate weeks by Mill Road Maternity Hospital and the Liverpool Maternity Hospital. The annual birth rate over the past 10 years has been within the range 14000 to 16000 , with no figures before this available for comparison. Home deliveries during the same period have fallen from 839 in 1975 to 69 in 1983, so that they now represent only $0.5 \%$ of the total (Mersey Regional Health Authority, personal communication).

Records of 860 calls made to the obstetric flying squad exist for Mill Road Maternity Hospital for 1965 to 1984 and for Liverpool Maternity Hospital for 1967 to 1984. Calls originated from the general practitioner, midwife, or ambulance crews. The squad team consists of one or more obstetricians and one or more anaesthetists of registrar grade or above, a senior midwife, and the ambulance staff. Before leaving the hospital they always attempt to ensure that their absence is covered adequately. The equipment carried would, in theory at least, allow any surgical manoeuvre to be performed under local or general anaesthetic, and provision is made for resuscitation and ventilation of both the mother and the neonate, should it be necessary.

\section{Results}

Table I shows the main findings, comparing figures for the earliest available full five years of Liang's review, 1967-71, with those for the last five years of our survey.

TABLE I-Reasons for calling obstetric flying squad, number of calls attended, and number of patients admitted. Values are numbers (\%) of women unless otherwise stated

\begin{tabular}{lrc}
\hline & $1967-71$ & $1980-4$ \\
\hline Number of calls attended & $317(100)$ & $149(100)$ \\
Complications: & $183(58)$ & $18(12)$ \\
$\quad$ Third stage & $39(12)$ & $73(49)$ \\
$\quad$ Antepartum & $69(22)$ & \\
Difficulties in labour requiring: & $79(25)$ & \\
$\quad$ Transfusion & $8(3)$ & $12(8)$ \\
$\quad$ General anaesthesia & $183(58)$ & $149(100)$ \\
Pre-eclampsia & & \\
Number of patients admitted & & \\
\hline
\end{tabular}

Number of calls made-This has now decreased to fewer than half of the number of calls made 20 years ago (table II). During these 20 years the number of home deliveries decreased dramatically to only 69 in 1983, the last year for which records are available. Today few calls, if any, are ever made to ask for attendance at such intended confinements. Thus the best comparison was taken to be the calls asking for the squad to attend difficulties in labour, which amounted to $64(8 \%)$. The original figure in the Bellshill study was $8 \%$ in the first 10 years and $0.2 \%$ in the second 10 . In these 64 cases the last general anaesthetic was given in 1972 and the last forceps delivery was in 1980. This forceps delivery was occasioned only by the patient's persistent refusal to be admitted to hospital and a prolonged second stage of labour with neither fetal nor maternal distress. Since then all calls have resulted in either the baby being born before arrival of the squad or uneventful transfer to hospital for further assessment.

Third stage complications-The early years (1965-71) show a remarkable similarity in the incidence of third stage complications to that in the earlier surveys, such complications representing $50-60 \%$ of all calls compared with the Bellshill figure of $59 \%$ over 20 years. Since 197.1, however, both the total number of calls and the proportion of calls because of these complications have declined to such an extent that they now represent less than $10 \%$ of the total (table II).

Antepartum haemorrhage and abortion-Though the total number of calls has altered very little over the years, the proportion of calls made because of antepartum haemorrhage has increased sharply, virtually exchanging places with the calls made because of third stage complications over the 20 years.
The Bellshill survey showed that antepartum haemorrhage accounted for $6 \%$ of calls; our figure was $25 \%$ (table II). Abortion accounted for $17 \%$ of calls in the Bellshill series and $11 \%$ in our survey. Clearly calls are now being made predominantly in an effort to anticipate problems developing rather than to deal with any problems that have already arisen.

General anaesthesia-The early years of our survey showed a $20-30 \%$ incidence of general anaesthesia in home deliveries, paralleling the figures from Bellshill. With the decline in complications of the third stage of labour, however, especially those caused by a retained placenta, has come a similar $\mathscr{D}$ decline in number of deliveries in which anaesthetics are administered; indeed, the last anaesthetic was given in 1977 (table II). This has led

TABLE II-Total number of calls made to obstetric flying squad, numbers of third stage complications and antepartum haemorrhages occurring, and numbers of blood transfusions and general anaesthetics given 1965-84

\begin{tabular}{|c|c|c|c|c|c|}
\hline \multirow[b]{2}{*}{ Year } & \multirow[b]{2}{*}{$\begin{array}{l}\text { Total No } \\
\text { of calls }\end{array}$} & \multicolumn{2}{|c|}{ No of women with complications } & \multicolumn{2}{|c|}{$\begin{array}{l}\text { No of women treated for } \\
\text { difficulties during labour }\end{array}$} \\
\hline & & Third stage & $\begin{array}{l}\text { Antepartum } \\
\text { haemorrhage }\end{array}$ & $\begin{array}{l}\text { Blood } \\
\text { transfusion }\end{array}$ & $\begin{array}{c}\text { General } \\
\text { anaesthetic }\end{array}$ \\
\hline 1965 & $47^{\star}$ & 29 & 6 & 17 & 10 \\
\hline 1966 & 46 & 25 & 5 & 23 & 8 \\
\hline 1967 & 76 & 48 & 4 & 19 & 19 \\
\hline 1968 & 64 & 35 & 10 & 15 & 16 \\
\hline 1969 & 61 & 38 & 6 & 15 & 19 \\
\hline 1970 & 65 & 36 & 11 & 9 & 14 \\
\hline 1971 & 51 & 26 & 8 & 11 & ii \\
\hline 1972 & 74 & 23 & 16 & 14 & 5 \\
\hline 1973 & 47 & 10 & 11 & 1 & 3 \\
\hline 1974 & 35 & 17 & 11 & 1 & 12 \\
\hline 1975 & 32 & 10 & 11 & 2 & 2 \\
\hline 1976 & 34 & 10 & 15 & 4 & 4 \\
\hline 1977 & 30 & 6 & 10 & & 1 \\
\hline 1978 & 24 & 6 & 11 & 2 & \\
\hline 1979 & 26 & 2 & 10 & 1 & \\
\hline 1980 & 27 & 4 & 15 & & \\
\hline 1981 & 48 & 6 & 21 & 1 & \\
\hline 1982 & 27 & 4 & 13 & & \\
\hline 1983 & 21 & 2 & 11 & & \\
\hline 1984 & 26 & 2 & 13 & & \\
\hline
\end{tabular}

^Mill Road Hospital only.

inevitably to unfamiliarity with the equipment carried and an increasing reluctance by the occasional anaesthetist to administer any anaesthetic in such hazardous circumstances, especially after successive maternal mortality reports have highlighted anaesthesia as a main contributory factor to their figures. ${ }^{14}$ The spread of continuous regional analgesic techniques for obstetric inpatients has created further problems for the anaesthetist, who must continue to bear responsibility for patients' treatment should he leave the hospital, for however short a period, before the arrival of replacement cover for his absence.

Blood transfusion-For several reasons blood transfusion, following the patterns of third stage complications and general anaesthesia, no longer plays any routine or large part in the management of the patients attended by the obstetric flying squad. Even after loss of blood most clinicians now prefer to transfer rapidly such patients to the maternity unit for better assessment before transfusion, restricting themselves in the mean time to giving an $\mathrm{N}$ intravenous infusion of crystalloid solution. From 1965 to 1972,126 patients (26\%) received a mean transfusion of 1.5 units/patient, but from 1973 to 1984 only nine patients $(2 \%)$ received blood, the last in 1981 for non-obstetric problems. This compares with $56 \%$ of the Bellshill patients receiving a mean transfusion of 1.5 units/patient (table II).

Pre-eclamptic toxaemia and eclampsia-Over 20 years 38 calls $(4 \%)$ have been made to request attendance on patients with these conditions, though 0 the incidence has increased slightly over the second 10 years to $8 \%$ of the total. This compares with $7 \%$ overall in the Bellshill survey. All but one of our patients have been successfully transferred to hospital with or without $T$ prior sedation. The exception was a patient who, almost uniquely, was transferred to a maternity unit other than those of the Liverpool Maternity Hospital or Mill Road Hospital, having been paralysed, intubated, and ventilated before transfer. The precise reasons for this have not been established, and the case records have been lost to follow up.

Patients admitted-Admission to hospital is now offered routinely to all patients on whom we are called to attend, regardless of the reason. It would now be considered to be indefensible to leave any such patients at home even with regular midwifery services present, unlike the early years, when many patients who had had general anaesthesia and blood transfusion during a 
home delivery were left to recover at home under the supervision of a district midwife. In 1965 about half of the patients were admitted to hospital; over 20 years this has increased until in 1979 all the patients were admitted. Since then this policy of admitting all patients has continued. The Bellshill survey showed only a $36 \%$ incidence of admission to hospital.

\section{Discussion}

The past 20 years have seen appreciable changes in both the number and the nature of the calls received by the urban obstetric flying squad in Liverpool. The early years of this survey produced figures very similar to those of the Bellshill review and other reviews of the 1940 s and 1950 s, but profound changes have taken place since then.

The urban obstetric flying squad is no longer a means of active intervention in complicated labours and deliveries or of gross resuscitation of mother and baby but has become more a means of careful assessment and transfer of patients who may develop severe problems to a nearby fully equipped centre, never more than 15 minutes away by ambulance. Patients no longer require routine delivery, transfusion, or general anaesthesia at home, and skill in such manoeuvres may now be lacking among obstetric, anaesthetic, and midwifery staff, as was confirmed by the results of the 1980 survey, by the Royal College of Obstetricians and Gynaecologists, of maternity units providing obstetric flying squads. ${ }^{13}$

The results of our review suggest that, though such services may continue to have a role in isolated rural communities, their provision in urban communities may not be justified in their present form. The transfer of patients who call the service to hospital for specialist care may seem to be desirable, but when this is balanced against the delay resulting from a second call to the hospital, the organisation of cover for the team members, the collection of equipment, and the journey being made in the knowledge that some members of the team are unfamiliar with the use of the equipment carried, that desirability is open to question, especially when a direct journey to hospital in the first place would be rapid, and the hospital could receive adequate warning to prepare to receive the patient. In many cases insurance cover for the staff taking part in the squad call has been found to be inadequate, especially when the risks of personal injury from possible road traffic accidents on the way to or from the scene are considered. In addition, the present numbers of staff in many maternity hospitals may not allow a full team to depart without endangering patients already in the hospital, many of whom require constant supervision.

We therefore recommend that all obstetric flying squads should be critically reviewed with regard to each area served to see whether they are still required or whether the problems encountered could be dealt with adequately by the emergency services already in existence. We think that the presence of an anaesthetist in the squad is now an unnecessary luxury that may have detrimental effects on obstetric inpatients.

\section{References}

1 Thompson HJ. Maternity emergency services. $\mathrm{Br}$ Med $\mathcal{f} 1936$;i:235

2 Murray EF. The organisation of a maternity service. $B r M e d ~ f 1929 ;$;:691-2.

3 Stabler F. The Newcastle upon Tyne obstetric emergency services. Br Med f 1947;ii:878-80.

4 Stabler F. The obstetric flying squad. BrMed f 1957;ii:217.

5 Dewhurst CJ. The emergency obstetrical service. A review of 489 cases in the Manchester area. Lancet 1952;ii:746-51.

6 Lloyd HN. Discussion on emergency obstetrical services (the flying squad). Its uses and abuses. Proceedings of the Royal Sociey of Medicine 1949;42:1-10.

7 Adamson TL, Brown R, Myerscough PR, Loudon JDO. The Edinburgh flying squad-a review. foumal of Obstetrics and Gynaecology of the British Empire 1960;67:243-8.

8 Frazer AC, Tatford EPW. Management of the third stage complications in domiciliary obstetrics. Lancet $1961 ;$ ii:126-9.

9 Liang DYS. The emergency obstetrical service, Bellshill Maternity Hospital 1933-61. Joumal of Obsterrics and Gynaecology of the British Commontwealth 1963;70:83-93.

10 Ferguson ILC, Watson JM. Assessment of the obstetric flying squad in an urban area. Br Med $\mathcal{f}$ 1976;:446-8.

11 James DK. Obstetric flying squad-a defence. BrMed $\mathcal{F}$ 1977;i:217-9.

12 Zorab J, Baskett P. Obstetric flying squads and mobile resuscitation units. Br Med J 1977;i: 773.

13 Royal College of Obstetricians and Gynaecologists. Survey of obstetric ftying squads. London: Royal College of Obstetricians and Gynaecologists, 1980.

14 Turnball AC, Tindall VR, Robson G, Dawson IMP, Cloake EP, Ashley JSA. Reports on health and sacial subjects, No 29. Report on confidential enquiries into maternal deaths in England and Wales 1979-1981. London: HMSO, 1986.

(Accepred 4 Nooember 1986)
Robert Muir's outstanding contributions to the science of pathology are well known. He was also a living example of a forthright character and a genuinely absent minded professor. If he went into his tobacconist's shop in Glasgow on the way to work he was quite likely to end the journey on foot, leaving his car with its engine running in the street. The police soon learnt to deliver it to the Western Infirmary. On one occasion his secretary sat for an hour in his study with her notebook open and her pencil poised while he looked steadily ahead. "That's all, Miss Selkirk," he said. When he was shown the blank page he replied, "Goodness me! I have just finished dictating a revised version of one of the chapters of my book."

Muir's department was made famous by his capacity to encourage and develop in others the talent and enthusiasm they already possessed. He was much in demand as an adviser and referee for the filling of vacant posts. He always took this responsibility seriously, and never lightly gave his name to act as referee for a candidate. When pressed by vice chancellors, as he often was, about the merits of candidates for whom he was not a referee he had one of two answers. Either it was "A good man, a very good man, and the right man for your job," or "A good man-yes-a good man; but not good enough for your job." He was strictly fair, never backing even a favourite pupil if he thought that the pupil was not the right man for a particular job. That was why his influence was so great and why his pupils filled so many chairs.

He was also a truly lovable and genuine character. When, on retirement, he came back from a world tour he was asked by a rather pompous visitor what had impressed him most during his journeyings. "Ah-Hollywood," he answered, "undoubtedly Hollywood." "Come, come, Muir," said his visitor, "surely something more significant than that." "Well," he replied thoughtfully, "there was that delightful Canadian custom of opening a bottle of whisky for the guests and throwing the cork in the fire."

One respected physician in the west end of Glasgow who was in practice at the time of Muir's appointment in 1899 told us, as Muir's juniors, how fortunate we were to work with so helpful a man. We pressed him about how helpful Muir was to a general practitioner like himself. "Oh, immensely helpful," he replied. "He was never in doubt about an opinion. I had a patient from abroad who was having intermittent fever and rigors. I made a blood smear and used one of these new Romanowsky's stains on it. I thought I saw malaria parasites and asked Muir if he could confirm my diagnosis. I pointed out the blue things I saw under the microscope." 'Ah these,' said Muir, 'these are leucocytes.' Such a clear diagnosis given without a moment's hesitation. You can have no idea how helpful it was to have so quick and clear an opinion from a consultant."

Pathology has come a long way since then, but Muir was undoubtedly one of those who gave it a good start. "I was well rewarded," he said in 1952; " $\$ 1200$ a year in 1912 - that's what I was paid. You can't match that today. I could afford to entertain the shipowners who did so much and so generously to give my department proper backing."-JAMES HOWIE. 